\title{
Estimated surge in hospital and intensive care admission because of the coronavirus disease 2019 pandemic in the Greater Toronto Area, Canada: a mathematical modelling study
}

\author{
Sharmistha Mishra MD PhD, Linwei Wang MSc, Huiting Ma MSc, Kristy C.Y. Yiu MSc, \\ J. Michael Paterson MSc, Eliane Kim MPH, Michael J. Schull MD MSc, Victoria Pequegnat MSc, \\ Anthea Lee MMA, Lisa Ishiguro MSc, Eric Coomes MD, Adrienne Chan MD MPH, Mark Downing MD, \\ David Landsman BSc, Sharon Straus MD MSc, Matthew Muller MD PhD
}

\section{Abstract}

Background: In pandemics, local hospitals need to anticipate a surge in health care needs. We examined the modelled surge because of the coronavirus disease 2019 (COVID-19) pandemic that was used to inform the early hospital-level response against cases as they transpired.

Methods: To estimate hospital-level surge in March and April 2020, we simulated a range of scenarios of severe acute respiratory syndrome coronavirus 2 (SARS-CoV-2) spread in the Greater Toronto Area (GTA), Canada, using the best available data at the time. We applied outputs to hospital-specific data to estimate surge over 6 weeks at 2 hospitals (St. Michael's Hospital and St. Joseph's Health Centre). We examined multiple scenarios, wherein the default $\left(R_{0}=2.4\right)$ resembled the early trajectory (to Mar. 25,2020$)$, and compared the default model projections with observed COVID-19 admissions in each hospital from Mar. 25 to May 6, 2020.

Results: For the hospitals to remain below non-ICU bed capacity, the default pessimistic scenario required a reduction in nonCOVID-19 inpatient care by $38 \%$ and $28 \%$, respectively, with St. Michael's Hospital requiring 40 new ICU beds and St. Joseph's Health Centre reducing its ICU beds for non-COVID-19 care by $6 \%$. The absolute difference between default-projected and observed census of inpatients with COVID-19 at each hospital was less than 20 from Mar. 25 to Apr. 11; projected and observed cases diverged widely thereafter. Uncertainty in local epidemiological features was more influential than uncertainty in clinical severity.

Interpretation: Scenario-based analyses were reliable in estimating short-term cases, but would require frequent re-analyses. Distribution of the city's surge was expected to vary across hospitals, and community-level strategies were key to mitigating each hospital's surge.

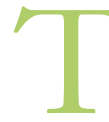

he coronavirus disease 2019 (COVID-19) pandemic caused by severe acute respiratory syndrome coronavirus 2 (SARS-CoV-2) has led to 127940 detected cases and 9117 deaths by Aug. 30, 2020, in Canada. ${ }^{1}$ By early March 2020, there was growing evidence from China of COVID-19 causing severe lung disease and critical illness requiring intensive care. ${ }^{2}$ Thus, an important component of responding to local onward transmission in Canada in March 2020 was preparing for a surge in inpatient and intensive care needs for patients with COVID-19.3-5

In Canada's health care system, national, provincial and local public health agencies provide guidance surrounding pandemic preparedness in the clinical setting, with implementation conducted within health care facilities. Decentralized implementation and hospital-level decision-making played a major role in the COVID-19 outbreak. ${ }^{6}$ Hospital-level pandemic planning teams integrated information on their local bed capacity, baseline admissions and anticipated surge to help prepare their respective hospitals. ${ }^{4}$

To support hospital-level pandemic planning in the Greater Toronto Area (GTA) during March and April 2020, we developed an epidemic model and used publicly available data and provincial administrative health care data to simulate

Competing interests: Eric Coomes is the co-principal investigator on a randomized controlled trial of chemoprophylaxis for COVID-19. This trial is funded by the Toronto COVID-19 Action Initiative and Thistledown Foundation. No other competing interests were declared.

Correspondence to: Sharmistha Mishra, sharmistha.mishra@utoronto.ca CMAJ Open 2020. DOI:10.9778/cmajo.20200093 
the range of plausible epidemic trajectories and hospital care needs anticipated for the GTA. We applied outputs from the epidemic model to hospital-specific data to estimate the early, 6-week trajectory and daily volume of inpatient and intensive care surge at 2 downtown, acute care hospitals in the GTA from Mar. 25 to May 6, 2020. We then compared the scenario-based projections to the observed hospital-specific COVID-19 inpatient census from Mar. 25 to May 6, 2020.

\section{Methods}

\section{Study setting}

The GTA has a population of 6 million and includes 5 regions $^{7-10}$ with 40 acute care hospitals. ${ }^{11}$ By Mar. 25, 2020, there were 544 diagnosed cases of COVID-19 in the GTA. ${ }^{12-17}$ St. Michael's Hospital (quaternary care) and St. Joseph's Health Centre (tertiary care) are part of Unity Health Toronto, a network of 2 acute care facilities and 1 long-term continuing care facility. The Unity Health Toronto COVID19 Incident Management Team was formed on Jan. 27, 2020, and requested rapid modelling in early March to estimate potential surge in health care needs at each hospital. Preliminary results were provided to the Incident Management Team on Mar. 4, 2020, and updated in late March using the constrained scenarios for a 6-week projection from Mar. 25 to May 6, 2020.

\section{Model design}

We developed a deterministic, compartmental, mathematical model of SARS-CoV-2 person-to-person transmission, and simulated a closed population (no births or deaths) over a 300day period. For the current analyses, we did not stratify the modelled population by age, and thus, we assumed a homogenous population. Figure 1 depicts the model structure, in which the biological component follows a susceptibleexposed-infectious-recovered system, and the health care component includes inpatient and intensive care unit (ICU) admissions. The model was written in $\mathrm{R}$ scripting language (source code available at our GitHub Repository ${ }^{18}$ ) and is detailed in Appendix 1, available at www.cmajopen.ca/ content/8/3/E593/suppl/DC1. An R-Shiny user interface was created for the model. ${ }^{19}$

Parameter values and their data sources are shown in Table 1. Appendix 1 details the biological, epidemiological and clinical severity parameters; internal validity checks (case fatality proportions and serial intervals); and epidemic constraints.

\section{Hospital-specific estimates}

To generate each hospital's catchment estimates over the anticipated months for the epidemic peak, we used ICES estimates on the median number (and interquartile range [IQR]) of hospital admissions and ICU admissions in the GTA and at each hospital from March to August 2019. ${ }^{11}$

For pre-outbreak inpatient bed use, Unity Health Toronto Decision Support provided daily census of non-ICU inpatients and ICU inpatients as a median (IQR) calculated over 90 days, using data from March to June of the years 2014 to
2019 (inclusive). It then provided inpatient census from Mar. 1, 2020, to May 6, 2020, for the comparison between the projected and actual census (Appendix 1).

\section{Intervention parameters}

We applied 2 GTA-wide interventions with assumptions surrounding their values: physical distancing to reduce contacts by $20 \%$ started 30 days into the outbreak, which was assumed to have seeded by Feb. 23, 2020, when at least 3 cases had been detected; and the proportion of nonsevere cases who self-isolated (default 10\%, via testing or syndromic diagnoses). Intervention parameters were fixed for the primary analyses and varied in sensitivity analyses ( 0 to $70 \%$ reduction in contact rate; delay initiating physical distancing from 2 to 90 days after start of outbreak; increasing the proportion with nonsevere infection who self-isolate from $10 \%$ to a maximum proportion of individuals with COVID-19 who may develop symptoms $[41 \%-69 \%]) .{ }^{47-49}$

\section{Epidemic constraints}

To generate a plausible range of epidemic trajectories under best- and worst-case scenarios, we sampled parameters as per Table 1 while fixing the intervention parameters. We used the following constraints: the upper and lower bound of the per-capita, cumulative cases detected per day in Lombardy, Italy, ${ }^{61}$ and Hong Kong, China, ${ }^{62}$ respectively, within the first 30 days after detection of 3 cases. We then selected a slow or small epidemic and a fast or large epidemic using the lower and upper IQR in the peak incidence across the full constrained set of epidemic trajectories. We defined a default scenario using the median or best-justified parameter values that passed our internal validity checks and epidemic constraints. We evaluated the face validity of our default epidemic by comparing it to our synthesis of the GTA data available as of Mar. 25, 2020, in which the first 3 cases had been detected by Feb. 23, 2020 (Appendix 1). ${ }^{12-17,63}$

\section{Statistical analysis}

We reported epidemic features and estimated health care needs across the range of plausible scenarios and the 3 selected scenarios for the GTA. We applied GTA model outputs from the 3 scenarios to generate hospital-specific estimates using the catchment proportion for non-ICU and ICU hospital admissions and added the baseline daily (median) number of inpatients on all non-ICU and ICU units for each hospital. We then compared the potential trajectories, under the assumption that baseline admissions remain the same, with the maximum capacity for non-ICU and ICU beds at each hospital. We performed a 1-way sensitivity analysis using the default scenario to identify the main sources of uncertainty when estimating hospital surge.

\section{Ethics approval}

This study was exempt from research ethics approval as the aggregate data provided by Unity Health Toronto Decision Support was not used to investigate a hypothesis systematically, and thus, it was not considered human research as 


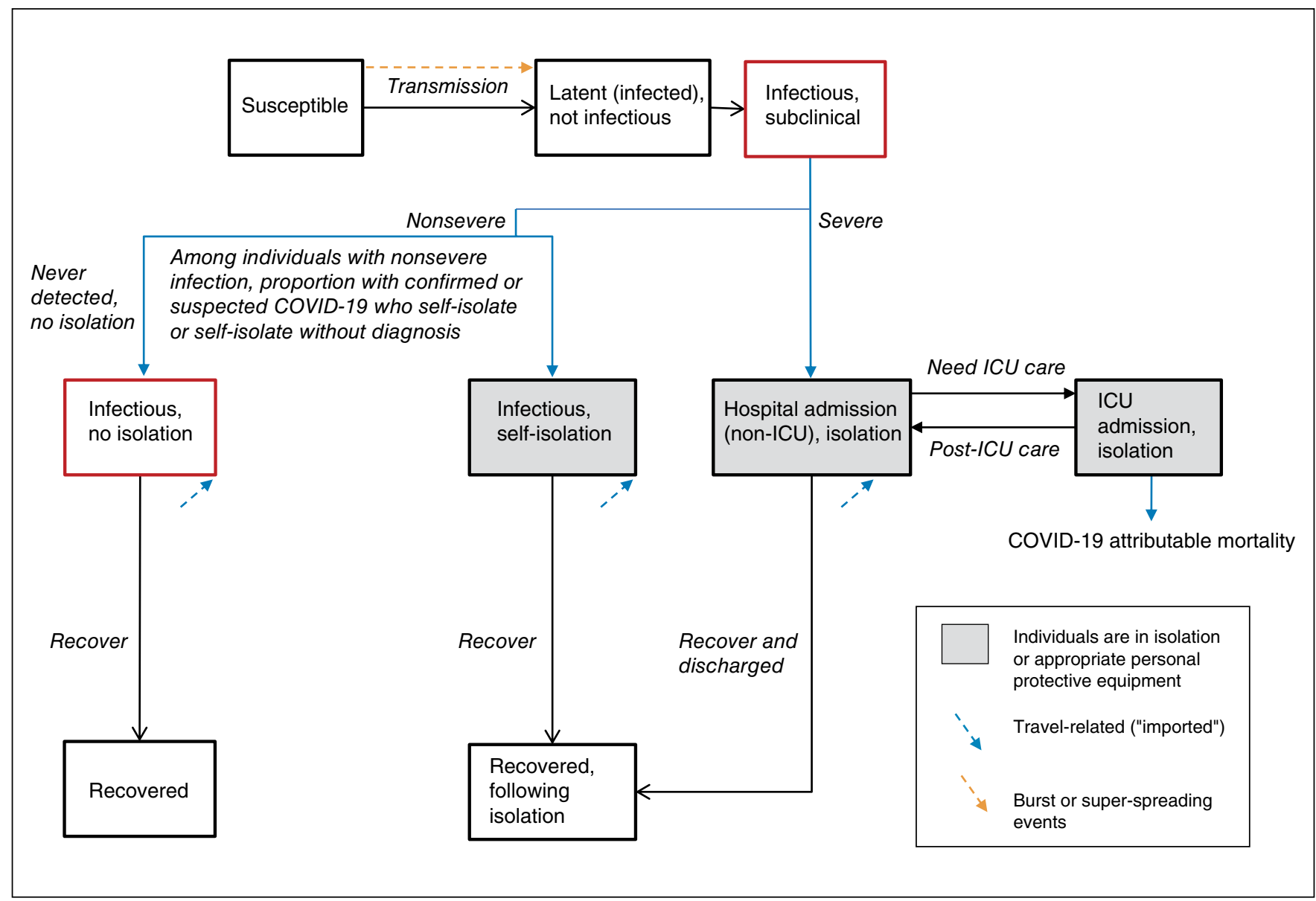

Figure 1: Transmission model structure. Compartments represent health states, with transitions between health states in a stable population of fixed size. A proportion of individuals infected with severe acute respiratory syndrome coronavirus 2 (SARS-CoV-2) develop severe coronavirus disease 2019 (COVID-19) and require admission to hospital. Among individuals with nonsevere COVID-19, a proportion self-isolate after receiving a diagnosis of confirmed or syndromic COVID-19 or may self-isolate without a diagnosis; the remainder do not self-isolate. Only a subset of individuals with nonsevere COVID-19 receive a confirmed diagnosis if they undergo testing. Individuals in the infectious health states may pass the virus on to others. We assume that individuals in self-isolation or hospital-isolation cannot pass on the virus, but superspreading events are included to capture community, long-term care and nosocomial (hospital-acquired) clusters of transmission events. Note: ICU = intensive care unit.

defined in the Tri-Council Policy Statement: Ethical Conduct for Research Involving Humans (TCPS 2) by the Unity Health Toronto Research Ethics Board Chair who reviewed our application for waiver.

\section{Results}

Figure 2 depicts the per-capita cumulative rate of confirmed cases across the plausible range of epidemics in the first 60 days of the outbreak, in the absence of further intervention. The default scenario followed a similar early trajectory of rapid growth in observed cases in the GTA, although the fast or large and slow or small epidemics were closer to, but not at the level of Lombardy and Hong Kong, respectively (Figure 2).

Parameter values for the 3 scenarios are compared in Appendix 2, Supplemental Table 2.1, available at www.cmaj open.ca/content/8/3/E593/suppl/DC1. The slow or small epidemic had a smaller $\mathrm{R}_{0}$ of 1.84 versus 2.4 in the default scenario. Transmission-related parameters were similar in the fast or large and default scenarios, except for a slightly higher proportion of the population already infected with COVID-19 at the start of the outbreak (initial seeding, $0.004 \%$ v. $0.003 \%$ in the default scenario). However, cumulative confirmed cases (Figure 2; Appendix 2, Supplemental Figure 2.1) were much lower in the default scenario because of the clinical parameters: the proportion of individuals with COVID-19 with severe disease requiring admission to hospital and thus, detected, was $10.4 \%$ in the fast or large versus $5.5 \%$ in the default scenario.

Appendix 2, Supplemental Figure 2.2 shows the epidemic curves in the absence of further interventions, wherein the default represented a pessimistic scenario. Appendix 2, Supplemental Table 2.2 summarizes the peak number of admissions and peak in daily census of inpatients in the GTA.

\section{Hospital-specific surge estimates}

Between March and August 2019, St. Michael's Hospital and St. Joseph's Health Centre received $4.5 \%$ (95\% confidence 
Table 1 (part 1 of 2): Transmission model parameters

\begin{tabular}{|c|c|c|c|c|}
\hline Variable & Units & Default value & $\begin{array}{l}\text { Range examined in } \\
\text { sensitivity analyses } \\
\text { (uniform distribution) }\end{array}$ & Reference and notes \\
\hline \multicolumn{5}{|l|}{ Epidemiological } \\
\hline Population size of the GTA & Number & 6196731 & NA & $\begin{array}{l}\text { Projected estimate from } 2016 \text { census }^{7,8} \text { and a } 1 \% \text { annual } \\
\text { change as per the United Nations Urbanization Prospects, }{ }^{9} \\
\text { and using the census metropolitan area of Toronto. }{ }^{10}\end{array}$ \\
\hline $\mathrm{R}_{0}$ & Number & 2.4 & $1.4-3.0$ & $\begin{array}{l}\text { Range of estimates from modelling studies of outbreaks within } \\
\text { and outside China, and on the Diamond Princess cruise } \\
\text { ship. }{ }^{20-24} \text { The lower bound was based on the lower bound } \\
\text { estimate of } R_{0} \text { from the World Health Organization report of } \\
\text { outbreaks in China. }{ }^{25} \text { Systematic review and meta-analysis of } \\
\text { studies of } R_{0} \text { suggest that } R_{0} \text { estimates have stablized in the } \\
\text { range of } 2-3 \text { in more recent studies. }{ }^{26} \text { Our default estimate of } \\
2.4 \text { was consistent with the assumption used in other } \\
\text { modelling studies. } .^{27}\end{array}$ \\
\hline Incubation period & Days & 5.2 & $3-9$ & $\begin{array}{l}\text { Pooled analysis of } 181 \text { confirmed cases with identifiable } \\
\text { exposure and symptom onset estimated a median incubation } \\
\text { of } 5.2 \text { days. }{ }^{28} \text { We further extracted point (mean or median) } \\
\text { estimates of incubation period from a list identified of studies in } \\
\text { China and Singapore to inform the range estimates. } .^{20,29-38}\end{array}$ \\
\hline Duration of latent infection & Days & 2 & $1-3$ & $\begin{array}{l}\text { Assumption based on the relatively short incubation period } \\
(5.2 \mathrm{~d}) \text { and serial interval }(4.4 \mathrm{~d}) \text { of COVID-19; other models } \\
\text { have used a latent period of } 3 \text { days. }{ }^{39}\end{array}$ \\
\hline $\begin{array}{l}\text { Duration of subclinical } \\
\text { infectiousness }\end{array}$ & Days & 3 & $2-6$ & $\begin{array}{l}\text { Calculated as the difference between incubation period and } \\
\text { latent period (Appendix 1, available at www.cmajopen.ca/ } \\
\text { content/8/3/E593/suppl/DC1). }\end{array}$ \\
\hline $\begin{array}{l}\text { Duration of symptomatic } \\
\text { infectiousness }\end{array}$ & Days & 7 & $5-10$ & $\begin{array}{l}\text { Based on duration of upper respiratory tract viral shedding } \\
\text { among individuals with symptoms. }{ }^{40}\end{array}$ \\
\hline Serial interval & Days & NA & $3.1-7.5$ & $\begin{array}{l}\text { No default estimate was used, as serial interval was not used } \\
\text { as an input parameter; only the range estimates were used for } \\
\text { internal parameter validation (detailed in the Methods } \\
\text { section). } .^{20,38,41,42}\end{array}$ \\
\hline Initial seeding & $\begin{array}{l}\% \text { of total } \\
\text { population }\end{array}$ & 0.0032 & $0.0011-0.0048$ & $\begin{array}{l}\text { Assumption on range based on detecting } 3 \text { travel-related } \\
\text { cases by Feb. } 23,2020 \text {, at a time when testing criteria was } \\
\text { limited to travel to China or contact with a person already } \\
\text { diagnosed with COVID- } 19,{ }^{43} \text { and likelihood of detection of } \\
\text { imported cases between } 11 \% \text { and } 40 \%{ }^{44} \text { We assumed } \\
\text { seeding includes imported cases from outside Canada, } \\
\text { between provinces and local transmission that had remained } \\
\text { undetected. }\end{array}$ \\
\hline \multicolumn{5}{|l|}{ Clinical } \\
\hline $\begin{array}{l}\text { Proportion diagnosed with } \\
\text { COVID-19 who required } \\
\text { admission to hospital }\end{array}$ & $\%$ & 10 & $6-20$ & $\begin{array}{l}\text { As of Mar. } 23,10 \% \text { of confirmed cases in Canada were } \\
\text { admitted to hospital. }{ }^{45} \text { Data on } 55924 \text { confirmed cases in } \\
\text { China suggested that } 19.9 \% \text { of confirmed cases were severe, } \\
\text { including } 6.1 \% \text { in critical conditions. }{ }^{34} \text { We therefore assumed } \\
\text { that a range from } 6 \% \text { to } 20 \% \text { of detected cases would require } \\
\text { admission to hospital in the GTA. Subsequently, Toronto Public } \\
\text { Health reported } 18(6.4 \%) \text { cases admitted to hospital out of } \\
280 \text { confirmed cases of COVID-19 as of Mar. } 24 .{ }^{46}\end{array}$ \\
\hline $\begin{array}{l}\text { Proportion infected with } \\
\text { SARS-CoV-2 who were } \\
\text { diagnosed }\end{array}$ & $\%$ & NA & $41-69$ & $\begin{array}{l}\text { Proportion infected who were diagnosed was not directly used } \\
\text { as an input parameter, but was used indirectly to calculate the } \\
\text { proportion infected who required admission to hospital } \\
\text { (detailed below). Analyses on data from China as well as on } \\
\text { Japanese citizens returning on repatriation flights showed that } \\
31 \%-59 \% \text { of infected cases may not be detected because of } \\
\text { asymptomatic infections or mild symptoms. } 47-49 \text { We therefore } \\
\text { assumed a default estimate of } 55 \% \text { (midpoint of the range) for } \\
\text { proportion of infected cases that were detected. }\end{array}$ \\
\hline
\end{tabular}


Table 1 (part 2 of 2): Transmission model parameters

\begin{tabular}{|lll} 
& & Range examined in \\
& sensitivity analyses & \\
Variable & Units $\quad$ Default value (uniform distribution) & Reference and notes \\
\hline
\end{tabular}

\section{Clinical (cont'd)}

Proportion infected with $\%$

SARS-CoV-2 who required

$5.5 \quad 2.4-14$

admission to hospital

$\begin{array}{llll}\text { Proportion admitted to } & \% & 33 & 30-52\end{array}$

hospital who require ICU

care

5.5 $\quad$ 2.4-14 We calculated the proportion of infected individuals who
require admission to hospital using the proportion of detected cases that require admission to hospital, and multiplied by the proportion of infected cases that may be detected.

\begin{tabular}{|c|c|c|c|c|}
\hline & & & & $\begin{array}{l}\text { ICU care. }{ }^{45} \text { Based on data of } 55924 \text { confirmed cases in } \\
\text { China, cases with critical conditions, and thus those that may } \\
\text { require ICU care, comprise } 30 \% \text { of confirmed cases with } \\
\text { severe or critical conditions. }{ }^{34} \text { Of } 1590 \text { patients admitted to } \\
\text { hospital across } 575 \text { hospitals in China, } 254 \text { had severe } \\
\text { conditions, and } 52 \% \text { of these required ICU care or invasive } \\
\text { ventilation. }{ }^{30} \text { We did not estimate the proportion of ICU } \\
\text { patients among all patients admitted to hospital in China as } \\
\text { many patients were admitted for isolation only rather than } \\
\text { because of disease severity in the settings of China. }\end{array}$ \\
\hline Duration of hospital stay & Days & 12 & $10-13$ & $\begin{array}{l}\text { Among } 1032 \text { patients admitted to hospital, who did not require } \\
\text { ICU care across } 552 \text { hospitals in China, their median length of } \\
\text { hospital stay at the end of study follow-up was } 12 \text { (IQR 10-13) } \\
\text { days. }{ }^{31} \text { This estimate was consistent with the estimates on length } \\
\text { of hospital stay among discharged patients with COVID-19 } \\
\text { (regardless of ICU stay) in China and Europe. } .^{29,31,32,50-52}\end{array}$ \\
\hline Duration of ICU stay & Days & 8 & $5-13$ & $\begin{array}{l}\text { There are limited data on the length of ICU stay before transfer to } \\
\text { the medicine ward for post-ICU recovery. Of } 23 \text { ICU patients in } \\
\text { Wuhan, who were discharged to the medicine ward from the } \\
\text { ICU, their median length of stay in ICU was } 8 \text { (IQR 5-13) days. }{ }^{53}\end{array}$ \\
\hline $\begin{array}{l}\text { Case-fatality proportion } \\
\text { among those in ICU care }\end{array}$ & $\%$ & 38 & $17-62$ & $\begin{array}{l}\text { Of } 1590 \text { patients admitted to hospital across } 575 \text { hospitals in } \\
\text { China, } 131 \text { patients required ICU care or invasive ventilation, } \\
\text { and } 50 \text { ( } 38 \%) \text { of these patients died. }{ }^{30} \text { We also extracted } \\
\text { estimates from several studies in China and in Europe } \\
\text { regarding the crude mortality among ICU patients, which } \\
\text { ranged from } 17 \% \text { to } 62 \% .{ }^{31,34,51,52,54-57}\end{array}$ \\
\hline $\begin{array}{l}\text { Case-fatality proportion } \\
\text { among those diagnosed }\end{array}$ & $\%$ & NA & $0.8-4.24$ & $\begin{array}{l}\text { No default estimate was used, as case-fatality proportion } \\
\text { among those diagnosed was not used as an input parameter; } \\
\text { only the range estimates were used for internal parameter } \\
\text { validation (detailed in the Methods section). Our estimates of } \\
\text { the case-fatality proportion among those diagnosed were } \\
\text { informed by a range of evidence as shown below, accounting } \\
\text { for the uncertainty and heterogeneity in estimates by } \\
\text { geographic location and age. } \\
\text { As of Mar. } 23,2020 \text {, cases were reported in Canada with } 23 \\
\text { deaths, indicating a crude case fatality of } 1.1 \%{ }^{45} \text { Using crude } \\
\text { age-specific case-fatality among all confirmed cases in } \\
\text { China, }{ }^{58} \text { and adjusted for the age distribution of confirmed } \\
\text { cases in Canada as of Mar. } 23,{ }^{45} \text { we obtained an overall crude } \\
\text { case fatality of } 2.5 \% \text { in Canada. Estimates of case-fatality rate } \\
\text { among confirmed cases after adjusting for time lag to death } \\
\text { ranged from } 0.8 \% \text { in China excluding Hubei province, } 3.48 \% \text { in } \\
\text { China overall and } 4.24 \% \text { in other countries and regions. }{ }^{59} \\
\text { Analyses using data of cases on Diamond Princess cruise ship } \\
\text { estimated an infection fatality rate of } 0.5 \% \text { and case fatality } \\
\text { rate of } 1.1 \% \text { after adjusting for time lag to death, and } \\
\text { standardizing the age to approximate the age distribution } \\
\text { among confirmed cases in China. }{ }^{60}\end{array}$ \\
\hline
\end{tabular}

Note: COVID-19 = coronavirus disease 2019, GTA = Greater Toronto Area, ICU = intensive care unit, IQR = interquartile range, NA = not applicable, SARS-CoV-2 = severe acute respiratory syndrome coronavirus 2 . 


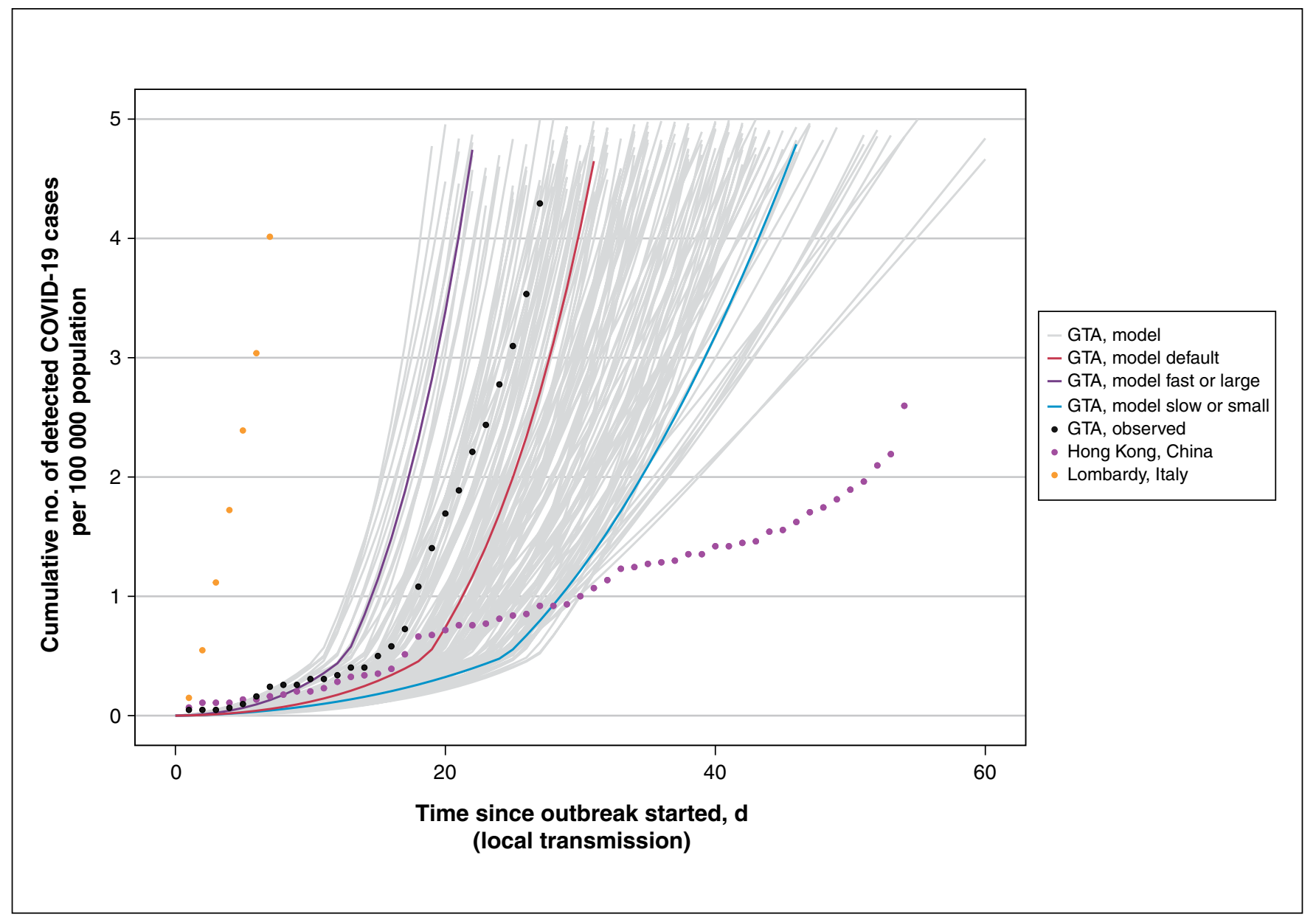

Figure 2: Cumulative detected cases per 100000 population across simulated epidemic scenarios and observed data used for epidemic constraints. Model outputs from the sampled range of parameters in Table 1, which meet the model constraints are shown for detected cases as solid lines. The observed data for Lombardy, Italy, ${ }^{61}$ and Hong Kong, China, ${ }^{62}$ are shown as dotted lines, and the corresponding data points at day 30 since the outbreak started were used as upper and lower bounds, respectively, to constrain the epidemics. The observed data on cumulative detected cases for the GTA (travel-related and local transmission) up to Mar. 20, 2020, are also shown (dashed black line) as part of the face validity check. The model output for the fast or large epidemic is shown via the purple solid line and slow or small epidemic via the blue solid line, selected as the upper and lower quartile of peak incidence, respectively, within the first 300 days. The default (solid red line) depicts the default scenario (Table 1). Simulated timeline begins at the start of the "seeding" of the population with $0.0011 \%-0.0048 \%$ of the population already infected with severe acute respiratory syndrome coronavirus 2 . For observed data, we defined the outbreak to have started when 3 confirmed cases were observed. We chose 3 cases detected as the onset of the epidemic based on the observed epidemic curve in the GTA, where the curve started to take off after detection of 3 cases (Feb. 23, 2020). We applied the same threshold for other regions for comparability of epidemic curves across geographic locations. Note: GTA $=$ Greater Toronto Area, COVID-19 = coronavirus disease 2019.

interval [CI] 4.4-4.6) and 3.9\% (95\% CI 3.8-4.0) of all nonICU hospital admissions in the GTA, respectively, and $8.7 \%$ (95\% CI $8.4-9.0)$ and $2.3 \%$ (95\% CI 2.1-2.5) of ICU admissions in the GTA, respectively. In the years from 2014 to 2019, the median daily non-ICU and ICU inpatient census at St. Michael's Hospital was 370-419 and 50-59, with a maximum capacity of 405 and 71 beds, respectively (Appendix 1). At St. Joseph's Health Centre, the median daily non-ICU and ICU inpatient census was 353-390 and 17-23, with a maximum capacity of 407 and 32 beds, respectively (Appendix 1).

The scenario-projected daily census of non-ICU and ICU inpatients, with or without COVID-19, is shown for each hospital in Appendix 2, Supplemental Figures 2.3-2.6. The model estimated that if nothing changed with the baseline (pre-outbreak) levels of admissions, both hospitals would surpass non-ICU and ICU capacity under the fast or large and default scenarios by May 6, 2020, but (as expected based on Appendix 2, Supplemental Figure 2.2) that would not be the case with the small or slow epidemic (Appendix 2, Supplemental Figures 2.3-2.6). Driven by differences in their catchment areas, it was expected that St. Michael's Hospital could have experienced an earlier surge around day 40 (May 27, 2020) and St. Joseph's Health Centre, a later surge around day 65 (Apr. 21, 2020).

Table 2 provides the estimated daily census of inpatients with COVID-19 from each scenario, the median and IQR of the full range of constrained model outputs for the catchment area of each hospital and the relative reduction in 
Table 2: Prevalent number of baseline* inpatients and inpatients with COVID-19 in non-ICU and ICU beds in 2 acute care hospitals in the Greater Toronto Area by May 6, 2020

Scenario-based projections

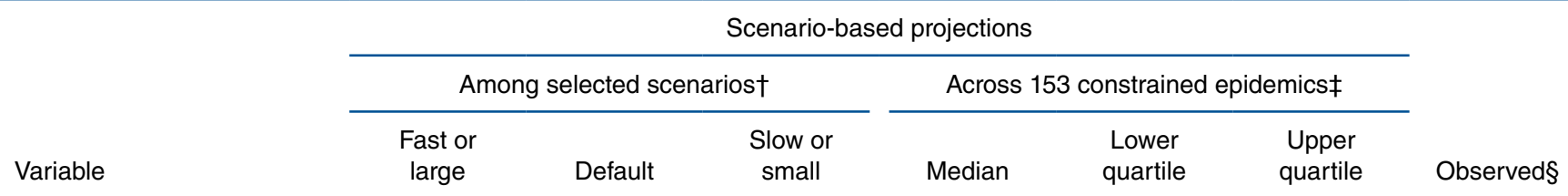

SMH non-ICU inpatient beds, $n$ (capacity $=405$; non-COVID-19 patients $=399^{*}$ )

\begin{tabular}{lcccccc}
$\begin{array}{l}\text { Daily prevalent number of } \\
\text { non-ICU COVID-19-related } \\
\text { inpatients, } n\end{array}$ & 989 & 156 & 5 & 43 & 9 & 211 \\
$\begin{array}{l}\text { Extra absolute number of } \\
\text { non-ICU beds needed, } n\end{array}$ & 983 & 150 & 0 & 37 & 3 & 205 \\
\hline $\begin{array}{l}\text { Projected reduction in } \\
\text { n }\end{array}$ & NA & 38 & 0 & 9 & 1 & 51
\end{tabular}

non-COVID-19, non-ICU

inpatients required to

remain below bed capacity,

and observed reduction§, \%

SMH ICU inpatient beds (capacity $=71$; non-COVID-19 patients $=56^{\star}$ )

\begin{tabular}{lcccccc}
$\begin{array}{l}\text { Daily prevalent number of } \\
\text { ICU COVID-19-related } \\
\text { inpatients, } n\end{array}$ & 493 & 55 & 7 & 25 & 5 & 129 \\
$\begin{array}{l}\text { Extra absolute number of } \\
\text { ICU beds needed, } n\end{array}$ & 478 & 40 & 0 & 10 & 0 & 114 \\
\hline $\begin{array}{l}\text { Projected reduction in } \\
\text { injes }\end{array}$ & NA & 71 & 0 & 18 & 0 & NA
\end{tabular}

Projected reduction in

non-COVID-19, ICU

inpatients required to

remain below bed capacity,

and observed reduction§, \%

SJHC non-ICU inpatient beds (capacity $=407$; non-COVID-19 patients $=374^{*}$ )

\begin{tabular}{lcccccr}
$\begin{array}{l}\text { Daily prevalent number of } \\
\text { non-ICU COVID-19-related } \\
\text { inpatients, } n\end{array}$ & 865 & 137 & 5 & 38 & 8 & 185 \\
$\begin{array}{l}\text { Extra absolute number of } \\
\text { non-ICU beds needed, } n\end{array}$ & 832 & 104 & 0 & 5 & 0 & 152 \\
\hline $\begin{array}{l}\text { Projected reduction in } \\
\text { n }\end{array}$ & NA & 28 & 0 & 1 & 0 & 41
\end{tabular}

non-COVID-19, non-ICU

inpatients required to

remain below bed capacity,

and observed reduction§, \%

SJHC ICU inpatient beds (capacity = 32; non-COVID-19 patients $=18^{\star}$ )

$\begin{aligned} & \text { Daily prevalent number of } \\ & \text { ICU COVID-19-related } \\ & \text { inpatients, } n\end{aligned}$
$\begin{aligned} & \text { Extra absolute number of } \\ & \text { ICU beds needed, } n\end{aligned}$

non-COVID-19 admissions or absolute increase in ICU beds needed to address the surge at each site. For St. Michael's Hospital to remain below its non-ICU bed capacity by
May 6, 2020, the default scenario projected that a $38 \%$ reduction in non-ICU, non-COVID-19 care was needed to open up 150 non-ICU inpatient beds; St. Michael's Hospital 
A

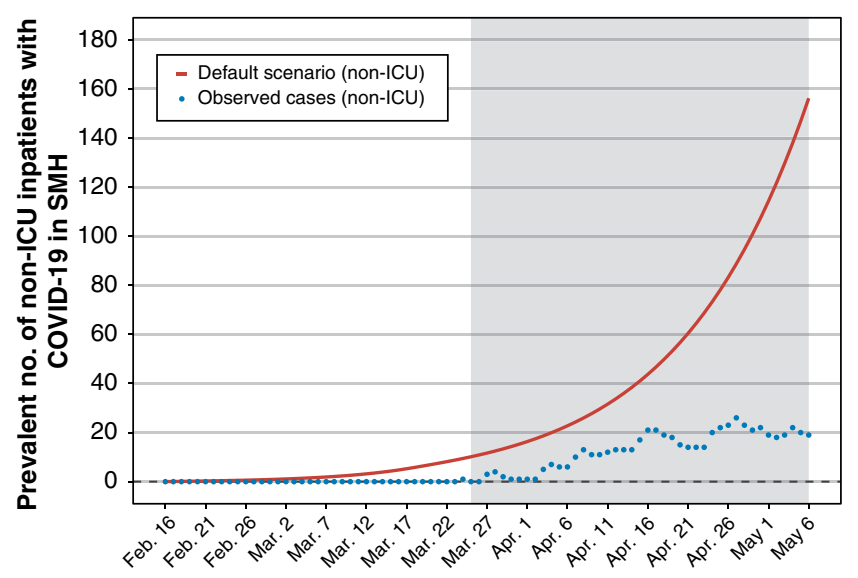

Calendar date (2020)

C

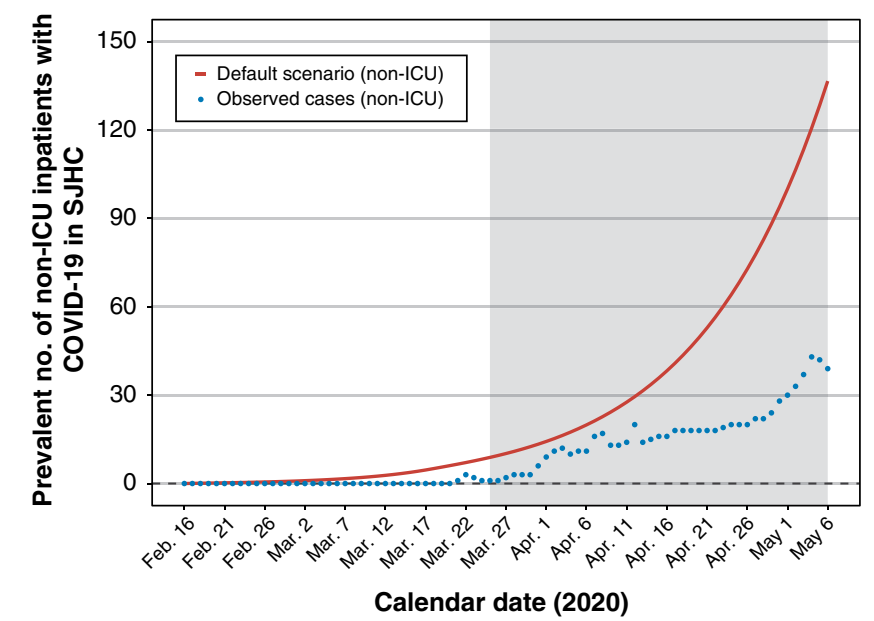

B

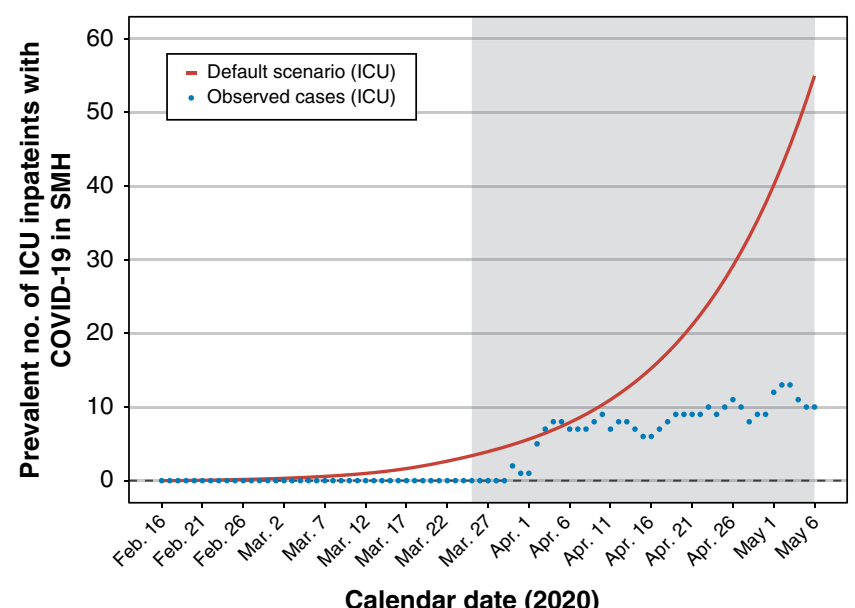

D

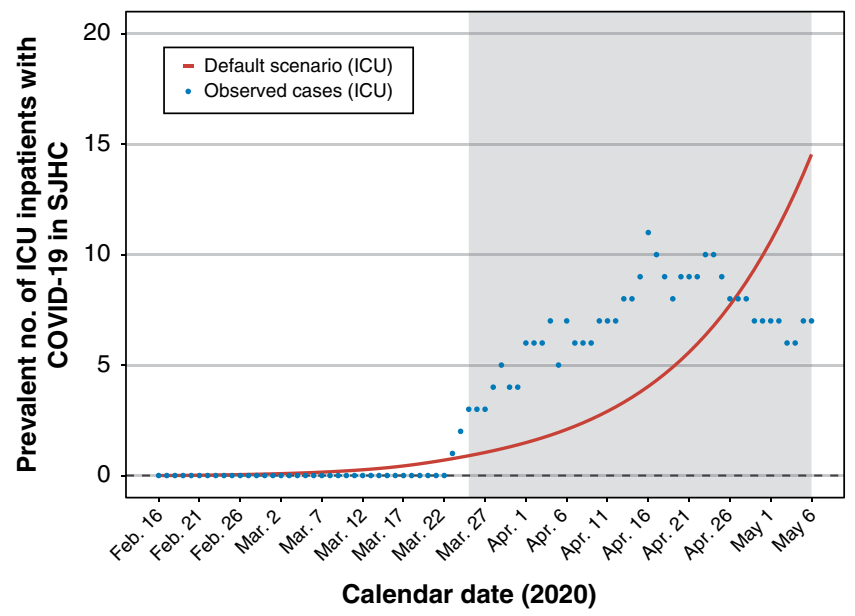

Figure 3: Estimated versus actual COVID-19 inpatient census at St. Michael's Hospital (SMH) and St. Joseph's Health Centre (SJHC) in the Greater Toronto Area. Model outputs from the default scenario. Observed data reflect the actual inpatient census of laboratory-confirmed cases of COVID-19. Results are shown for SMH (A) non-ICU inpatient census and (B) ICU census; and for SJHC (C) non-ICU inpatient census and (D) ICU census. The shaded area refers to the period of model projections used by each hospital in pandemic preparedness planning. Note: COVID-19 = coronavirus disease 2019, ICU = intensive care unit.

would also have to create 40 new ICU beds in addition to its current capacity of 71 beds to be able to care for nonCOVID-19 and new COVID-19-related ICU inpatients (Table 2). At St. Joseph's Health Centre, the default scenario projected a $28 \%$ reduction in non-ICU beds and $6 \%$ reduction in ICU-beds for non-COVID-19 care would be needed to open up 104 non-ICU beds and 1 ICU bed by May 6, 2020, and remain below the hospital's respective bed capacity (Table 2 ).

\section{Sensitivity analyses for hospital-specific surge estimates}

Results of 1-way sensitivity analyses for projected inpatient census are shown using the default scenario for St. Michael's Hospital in Appendix 2, Supplemental Figures 2.4-2.7. Results of sensitivity analyses were similar for St. Joseph's Health Centre. Uncertainty in local epidemiological features (such as local seeding and interventions) was more influential than uncertainty in clinical severity. For example, if physical distancing could reduce contact rates by only $20 \%$, then maximizing the diagnostic capacity or syndromic diagnosis at the community level in the GTA reduced the anticipated surge at St. Michael's Hospital from 156 to 31 non-ICU patients with COVID-19 and 55 to 12 ICU patients with COVID-19 by May 6, 2020 .

\section{Comparison of projected versus observed hospital- specific surge}

Figure 3 depicts the projected versus observed inpatient census for non-ICU and ICU patients with COVID-19 in each 


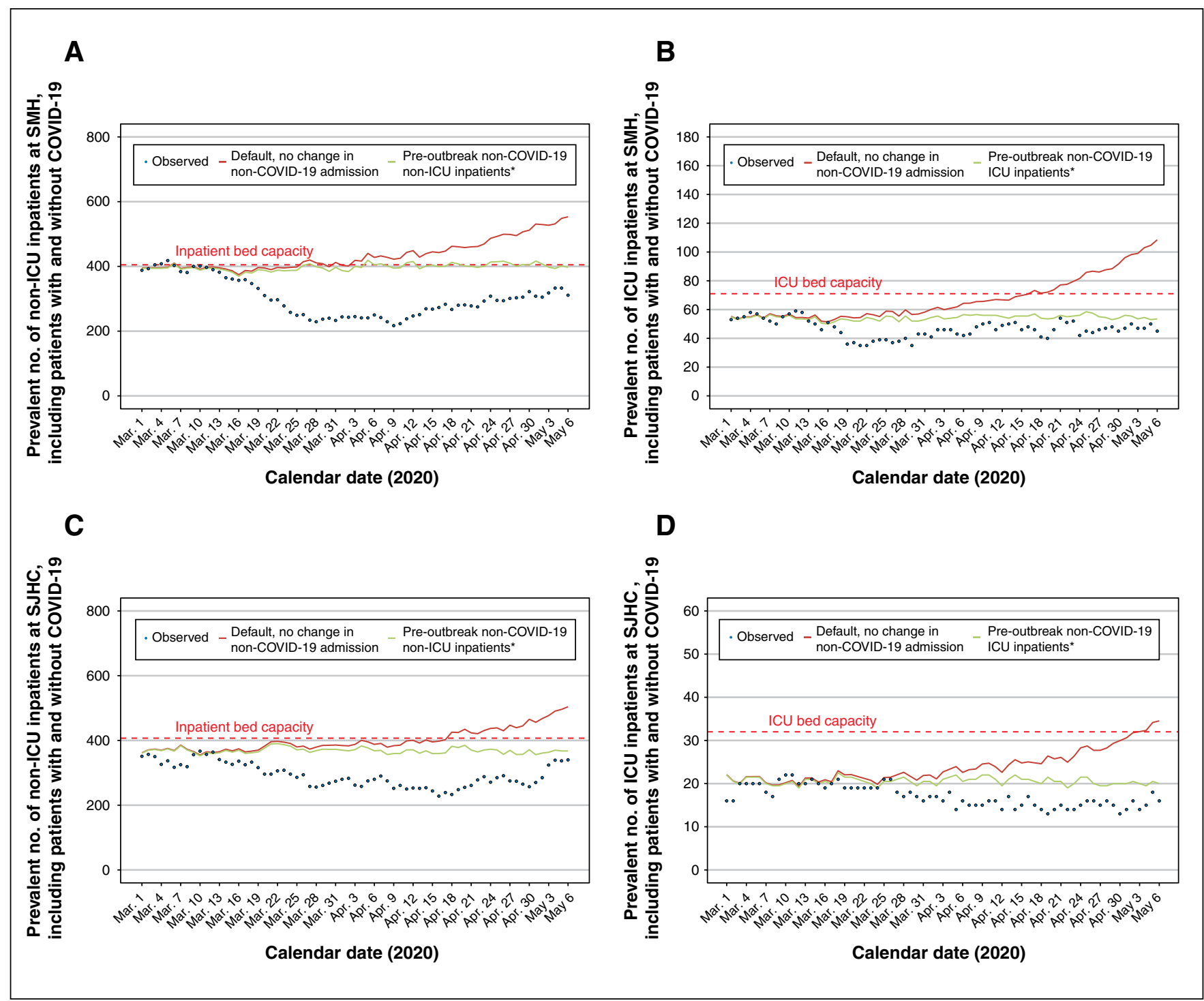

Figure 4: Estimated surge and capacity for non-ICU and ICU admissions to hospital at St. Michael's Hospital (SMH) and St. Joseph's Health Centre (SJHC) in the Greater Toronto Area. Model outputs from the default scenario under the assumption that pre-outbreak, non-COVID-19 admissions do not change. *Estimated by the median number of non-ICU inpatients at each hospital between March and June, 2014-2019. Observed data reflect the actual inpatient census up to May 6, 2020. Results are shown for SMH (A) non-ICU inpatient census and (B) ICU census; and for SJHC (C) non-ICU inpatient census and (D) ICU census. The dashed red line indicates the inpatient bed capacity. Note: COVID-19 = coronavirus disease 2019 , ICU = intensive care unit.

hospital. The default scenario anticipated the observed cases well in the short term (Mar. 25 to Apr. 11, 2020: absolute difference of $<20$ cases across hospitals and units) but diverged considerably thereafter. Figure 4 depicts the projected versus observed versus inpatient census including patients with COVID-19. The actual reduction in beds was sufficiently large (Table 2) that each hospital remained within their bed capacity by May 6, 2020.

\section{Interpretation}

Model projections of early COVID-19 spread anticipated a surge in admission to hospitals and ICU needs in the GTA. However, the impact of the city's outbreak was expected to vary across hospitals by their local catchment area, with local epidemic features driving each hospital's surge. The local transmission dynamics, or what was happening with the epidemic overall in the city with respect to community-level interventions, for example, had a larger influence on projected hospital surge than uncertainty around disease severity. Shortterm projections closely matched that which transpired in each hospital, but there was wide divergence thereafter.

Our estimates of the GTA and hospital surge aligned with estimates from other modelling studies conducted around the same time (provincial and national ${ }^{64}$ in Canada, and in other settings ${ }^{65}$ ). The preliminary hospital-specific findings (on Mar. 4, 2020) were used to prepare for the local surge at the 2 hospitals, with the updated analyses from 
Mar. 25, 2020, used to continue planning efforts. The hospitals opened up beds by temporarily cancelling non-essential surgeries and procedures. As most COVID-19-related inpatient care would fall under the hospitalist and medicine services, the relevant departments rapidly set up a separate service with a viable back-up system and ability for rapid scale up. Ambulatory clinics were reduced with a focus on virtual care and urgent assessments; this allowed clinic space to be consolidated to preserve personal protective equipment and human resources for deployment to other areas. This consolidation also allowed identification of potential inpatient spaces. There was also a change in health care use by the public: non-COVID-19 medicine admissions are dropping across the city and country. ${ }^{66}$ The active and passive reductions in admissions meant that neither hospital went over capacity.

\section{Limitations}

Our 6-week scenario-based analyses were conditional on maintaining a status quo in interventions achieved as of Mar. 27, 2020. The divergence in modelled surge versus observed cases beyond the first 3 weeks of analyses likely reflect the impact of community-based interventions or influence of other heterogeneities that were not accounted for in our model. For example, as outbreaks in long-term care facilities were detected in late March and early April, 2020, ${ }^{67}$ some residents with severe infections were not transferred to acute care hospitals based on residents' goals of care. ${ }^{68}$

We assumed that distribution of admissions would follow 2019 patterns and that transmission was homogenous across the city. However, distribution of admissions may be expected to follow even more granular patterns of transmission in each hospital's neighbourhood-level catchment area. ${ }^{69}$ Future work includes capturing heterogeneity within the 5 health units and near real-time adjustment of the catchment area using observed patterns of hospital-specific admissions; and heterogeneity in contact patterns by age-group and across congregate settings. As interventions become dynamic over time, future analyses of surge would also benefit from consideration of duration of protective immunity. ${ }^{70}$ Since our model was deterministic, we did not capture random chance, which is especially important with small number of cases as would be expected at the hospital-level. Finally, our objective was to conduct a scenario-based analyses and not to fit the model explicitly to observed cases, admissions to hospital, ICU admissions and deaths in the GTA. Future work involves adapting and fitting to population and setting-specific data on trends in testing, cases and outcomes in the GTA.

\section{Conclusion}

A surge in hospital capacity in the GTA was expected across a range of pessimistic to optimistic scenarios during the COVID-19 pandemic, with important and practical variability anticipated at the hospital level. Although short-term estimates of the surge were reliable, medium-term estimates would benefit from re-analyses as community-level interventions remain a critical driver in mitigating hospital-level surge.

\section{References}

1. Coronavirus disease (COVID-19). Ottawa: Government of Canada; 2020. Available: www.canada.ca/en/public-health/services/diseases/coronavirus-disease -covid-19.html (accessed 2020 Aug. 30).

2. World Health Organization. Report of the WHO-China joint mission on coronavirus disease 2019 (COVID-19). 2020.

3. Chopra V, Toner E, Waldhorn R, et al. How should U.S. hospitals prepare for coronavirus disease 2019 (COVID-19)? Ann Intern Med 2020;172:621-2.

4. Schull MJ, Stukel TA, Vermeulen MJ, et al. Surge capacity associated with restrictions on nonurgent hospital utilization and expected admissions during an influenza pandemic: lessons from the Toronto severe acute respiratory syndrome outbreak. Acad Emerg Med 2006;13:1228-31.

5. Pandemic preparedness. Geneva: World Health Organization; 2018. Available: www.who.int/influenza/preparedness/pandemic/en/ (accessed 2020 Mar. 31).

6. Lin M, Beliavsky A, Katz K, et al. What can early Canadian experience screening for COVID-19 teach us about how to prepare for a pandemic? CMAf 2020;192:E314-8.

7. Census profile, 2016 census - Toronto [census metropolitan area], Ontario and Ontario [province]. Ottawa: Statistics Canada; 2020. Available: www12.statcan.gc.ca/census -recensement/2016/dp-pd/prof/details/page.cfm?Lang=E\&Geo1=CMACA\&Code $1=535 \& \mathrm{Geo} 2=\mathrm{PR} \&$ Code $2=35 \&$ Data $=$ Count $\&$ Search Text $=$ Toronto $\&$ Search Type=Begins \&SearchPR=01\&TABID=1\&B1=All (accessed 2020 Mar. 24).

8. Toronto population 2020. World Population Review; 2020. Available: https://worldpopulationreview.com/world-cities/toronto-population/ (accessed 2020 Mar. 24).

9. World urbanization prospects 2018: highlights. New York: United Nations; 2019. Available: https://population.un.org/wup/Publications/Files/WUP2018 -Highlights.pdf? (accessed 2020 Mar. 31).

10. Census metropolitan area of Toronto, Ontario 2020. Ottawa: Statistics Canada; 2020. Available: www12.statcan.gc.ca/census-recensement/2011/as-sa/fogs-spg/Facts -cma-eng.cfm?LANG=Eng\&GK=CMA\&GC=535 (accessed 2020 Mar. 24).

11. Kim E, Paterson JM, Ischiguro L, et al. Surge planning for COVID-19 at the hospital level. Applied Health Research Question \#2020 0950074000. Toronto: ICES; 2020.

12. Yiu K, Lin W, Mishra S. COVID-19 GTA cumulative time series (as of March 25, 2020). GitHub; 2020. Available: https://github.com/mishra-lab/covid -GTA-surge-planning/blob/b5be48bf3b45e4fa3c0a3b1fc3101336eba31133/ data/time_series_19-covid_GTA_clean_Mar25.xlsx (accessed 2020 Apr. 17).

13. COVID-19: Official statements - Medical Officer of Health. Toronto: City of Toronto; 2020. Available: www.toronto.ca/home/covid-19/media-room/ moh-statements/ (accessed 2020 Mar. 27).

14. COVID-19 update. Whitby (ON): Durham Region; 2020. Available: www. durham.ca/en/health-and-wellness/novel-coronavirus-update.aspx\# (accessed 2020 Mar. 24).

15. COVID-19 (2019 novel coronavirus). Oakville (ON): Halton Region; 2020. Available: www.halton.ca/For-Residents/Immunizations-Preventable-Disease/ Diseases-Infections/New-Coronavirus (accessed 2020 Mar. 24).

16. Novel coronavirus (COVID-19). Brampton (ON): Region of Peel; 2020. Available: www.peelregion.ca/coronavirus/ (accessed 2020 Mar. 24).

17. COVID-19 in York Region. Newmarket (ON): York Region; 2020. Available: www.york.ca/wps/portal/yorkhome/health/yr/covid-19/covid19inyorkregion/01c ovid19inyorkregion/!ut/p/z1/tVXRcqIwFP2WffCRyU1AkzxmWSvQim5breb FYREhWwFLU61 v7GID-20MDsWHkKSOTn33pM7J0iiBZJFtFdppFVZR FuzXsrByhcj3_MuIZg4zAUBExEQymDIMbp7ARDiDDzsQgDehIF_Qaf9X8z DcEmQbD4_RxLJXazWaEnshLKYM4tCP7acKB5YHP9Zm4Fv-pxvIm7wBh0 XeqcztDxWq7gsdFLoHhzL6t4sHrXSTy8bWZknZkyirc56EJd7tbYwr2eYq-J0 okpSU2YPAH-yXZfWkPupNPjiE1CfbwDINmllWwj5nmN0wxzw5wEVczwBx 7drQMP1LE2S9Mssrgm626vkgGZFWeWmH27-87o8aIuAz4zQQm93Sk-h W3rSLf33iBP44GJxaj97aIMgvst-2gELw261D7vVPuxW-7Dbvp-fK07Q5k7m ZSDV2B2nhjbSmaWKTYkWb0Zbzz446uJzozVU6u_DgxTG20-G_qzRomtzf5 WPMld4YgRTuJ1R-D2kDhtcjadXZ7vSLp_lzD4q6_6aHW43WŽqvxkO73 TbpkwbrPjxDzbwgmQ!/dz/d5/L2dBISEvZ0FBIS9nQSEh/\#.XsqJEDpKhPY (accessed 2020 Mar. 24).

18. Ma H, Wang L, Landsman D, et al. COVID-19 GTA surge planning. GitHub; 2020. Available: https://github.com/mishra-lab/covid-GTA-surgeplanning (accessed 2020 Apr. 16).

19. Landsman D, Wang L, Ma H, et al. R Shiny tool for GTA hospital surge due to COVID-19. GitHub; 2020. Available: https://mishra-lab.shinyapps.io/ covid-GTA-surge-planning/ (accessed 2020 Apr. 16).

20. Li Q, Guan X, Wu P, et al. Early transmission dynamics in Wuhan, China, of novel coronavirus-infected pneumonia. N Engl f Med 2020;382:1199-1207.

21. Zhang S, Diao MY, Yu W, et al. Estimation of the reproductive number of novel coronavirus (COVID-19) and the probable outbreak size on the Diamond Princess cruise ship: a data-driven analysis. Int F Infect Dis 2020;93:201-4.

22. Jung SM, Akhmetzhanov AR, Hayashi K, et al. Real-time estimation of the risk of death from novel coronavirus (COVID-19) infection: inference using exported cases. 7 Clin Med 2020;9:523.

23. Zhao S, Cao P, Gao D, et al. Epidemic growth and reproduction number for the novel coronavirus disease (COVID-19) outbreak on the Diamond Princess cruise ship from January 20 to February 19, 2020: a preliminary data-driven analysis. SSRN 2020 Feb. 24. 
24. Shen M, Peng Z, Xiao Y, et al. Modelling the epidemic trend of the 2019 novel coronavirus outbreak in China. bioRxiv 2020 Jan. 25. doi: https://doi. org/10.1101/2020.01.23.916726.

25. Statement on the meeting of the International Health Regulations (2005) Emergency Committee regarding the outbreak of novel coronavirus $(2019-\mathrm{nCoV})$ [press release]. Geneva: World Health Organization; 2020 Jan. 23.

26. Liu Y, Gayle AA, Wilder-Smith A, et al. The reproductive number of COVID-19 is higher compared to SARS coronavirus. 7 Travel Med 2020;27:taaa021.

27. Ferguson NM, Laydon D, Nedjati-Gilani G, et al. Impact of non-pharmaceutical interventions (NPIs) to reduce COVID19 mortality and healthcare demand. London (UK): Imperial College London; 2020Mar. 16. doi: https://doi. org/10.25561/77482. Available: www.imperial.ac.uk/media/imperial-college/ medicine/sph/ide/gida-fellowships/Imperial-College-COVID19-NPI-modelling -16-03-2020.pdf (accessed 2020 Mar. 31).

28. Lauer SA, Grantz KH, Bi Q, et al. The incubation period of coronavirus disease 2019 (COVID-19) from publicly reported confirmed cases: estimation and application. Ann Intern Med 2020;172:577-82.

29. Fan Z, Chen L, Li J, Tian C, et al. Clinical features of COVID-19-related liver damage. medRxiv 2020 Feb. 28. doi: https://doi.org/10.1101/2020.02.26. 20026971.

30. Guan WJ, Liang WH, Zhao Y, et al. Comorbidity and its impact on 1,590 patients with COVID-19 in China: a nationwide analysis. medRxiv 2020 Feb. 27. doi: https://doi.org/10.1101/2020.02.25.20027664.

31. Guan WJ, Ni ZY, Hu Y, et al. Clinical characteristics of coronavirus disease 2019 in China. N Engl 7 Med 2020;382:1708-20.

32. Liu L, Gao JY, Hu WM, et al. Clinical characteristics of 51 patients discharged from hospital with COVID-19 in Chongqing, China. medRxiv 2020 Feb. 23. doi: https://doi.org/10.1101/2020.02.20.20025536.

33. Tian S, Hu N, Lou J, et al. Characteristics of COVID-19 infection in Beijing. 7 Infect 2020;80:401-6.

34. Report of the WHO-China joint mission on coronavirus disease 2019 (COVID-19). Geneva: World Health Organization; 2020.

35. $\mathrm{Xu} X W, \mathrm{Wu} X X$, Jiang $\mathrm{XG}$, et al. Clinical findings in a group of patients infected with the 2019 novel coronavirus (SARS-Cov-2) outside of Wuhan, China: retrospective case series. BMF 2020;368:m606.

36. You C, Deng Y, Hu WM, et al. Estimation of the time-varying reproduction number of COVID-19 outbreak in China. medRxiv 2020 Feb. 17. doi: https:// doi.org/10.1101/2020.02.08.20021253.

37. Backer JA, Klinkenberg D, Wallinga J. Incubation period of 2019 novel coronavirus (2019-nCoV) infections among travellers from Wuhan, China, 20-28 January 2020. Euro Surveill 2020;25:2000062.

38. Tindale LC, Coombe M, Stockdale JE, et al. Transmission interval estimates suggest pre-symptomatic spread of COVID-19. medRxiv 2020 Mar. 6. doi: https://doi.org/10.1101/2020.03.03.20029983.

39. Lin Q, Zhao S, Gao D, et al. A conceptual model for the coronavirus disease 2019 (COVID-19) outbreak in Wuhan, China with individual reaction and governmental action. Int 7 Infect Dis 2020;93:211-6.

40. Wolfel R, Corman VM, Guggemos W, et al. Virological assessment of hospitalized cases of coronavirus disease 2019. medRxiv 2020 Mar. 8. doi: https://doi.org/1 0.1101/2020.03.05.20030502.

41. Nishiura H, Linton NM, Akhmetzhanov AR. Serial interval of novel coronavirus (COVID-19) infections. Int f Infect Dis 2020;93:284-6.

42. Zhao S, Gao D, Zhuang Z, et al. Estimating the serial interval of the novel coronavirus disease (COVID-19): a statistical analysis using the public data in Hong Kong from January 16 to February 15, 2020. medRxiv 2020 Feb. 25. doi: https://doi.org/10.1101/2020.02.21.20026559.

43. Murti M, Whelan M, Saunders A, et al. Surveillance of persons who tested negative for COVID-19 in Ontario, January 22-February 22, 2020. Can Commun Dis Rep 2020;46:150-4.

44. Niehus R, De Salazar PM, Taylor AR, et al. Using observational data to quantify bias of traveller-derived COVID-19 prevalence estimates in Wuhan, China. Lancet Infect Dis 2020;20:803-8.

45. Coronavirus disease (COVID-19): outbreak update. Government of Canada; 2020. Available: www.canada.ca/en/public-health/services/diseases/2019novel-coronavirus-infection.html (accessed 2020 Mar. 24).

46. COVID-19. Toronto: City of Toronto; 2020. Available: www.toronto.ca/ home/covid-19/ (accessed 2020 Mar. 31).

47. Qiu J. Covert coronavirus infections could be seeding new outbreaks. Nature 2020 Mar. 20. Available: www.nature.com/articles/d41586-020-00822-x (accessed 2020 Mar. 23).

48. Nishiura H, Kobayashi T, Suzuki A, et al. Estimation of the asymptomatic ratio of novel coronavirus infections (COVID-19). Int 7 Infect Dis 2020; 94:154-5.

49. Wang C, Liu L, Hao X, et al. Evolving epidemiology and impact of non-pharmaceutical interventions on the outbreak of coronavirus disease 2019 in Wuhan, China. medRxiv 2020 Mar. 6. doi: https://doi.org/10.1101/2020.03.03.20030593.

50. Xiao K, Huang M, Zhan F, et al. Epidemiological and clinical features of 197 patients infected with 2019 novel coronavirus in Chongqing, China: a single center descriptive study. SSRN 2020 Feb. 19.

51. Wang D, Hu B, Hu C, et al. Clinical characteristics of 138 hospitalized patients with 2019 novel coronavirus-infected pneumonia in Wuhan, China. ҰAMA 2020;323:1061-9.
52. Spiteri G, Fielding J, Diercke M, et al. First cases of coronavirus disease 2019 (COVID-19) in the WHO European Region, 24 January to 21 February 2020. Euro Surveill 2020;25; 2000178.

53. Zhang GQ, Hu C, Luo LJ, et al. Clinical features and treatment of 221 patients with COVID-19 in Wuhan, China. SSRN 2020 Mar. 6. doi: https:// doi.org/10.1101/2020.03.02.20030452.

54. Yang X, Yu Y, Xu J, et al. Clinical course and outcomes of critically ill patients with SARS-CoV-2 pneumonia in Wuhan, China: a single-centered, retrospective, observational study. Lancet Respir Med 2020;8:475-81.

55. Wu Z, McGoogan JM. Characteristics of and important lessons from the coronavirus disease 2019 (COVID-19) outbreak in China: summary of a report of 72314 cases from the Chinese Center for Disease Control and Prevention. FAMA 2020.

56. Huang C, Wang Y, Li X, et al. Clinical features of patients infected with 2019 novel coronavirus in Wuhan, China. Lancet 2020;395:497-506.

57. Zhou W, Liu Y, Tian D, et al. Potential benefits of precise corticosteroids therapy for severe 2019-nCoV pneumonia. Signal Transduct Target Ther 2020;5:18.

58. Age, sex, existing conditions of COVID-19 cases and deaths 2020. Worldometer; updated 2020 Feb. 29. Available: www.worldometers.info/coronavirus/coronavirus-age-sex-demographics/ (accessed 2020 Mar. 23).

59. Wilson N, Kvalsvig A, Barnard LT, et al. Case-fatality risk estimates for COVID-19 calculated by using a lag time for fatality. Emerg Infect Dis 2020;26:1339-41.

60. Russell TW, Hellewell J, Jarvis C, et al. Estimating the infection and case fatality ratio for COVID-19 using age-adjusted data from the outbreak on the Diamond Princess cruise ship. medRxiv 2020 Mar. 9. doi: https://doi.org/10.1 101/2020.03.05.20031773.

61. COVID 19. Rome: Protezione Civile; 2020. Available: http://opendatadpc. maps.arcgis.com/apps/opsdashboard/index.html\#/dae18c330e8e4093bb090a b0aa2b4892 (accessed 2020 Aug. 31).

62. Latest situation of cases of COVID-19. Hong Kong: Centre for Health Protection, Department of Health; 2020. Available from: https://www.chp.gov. hk/files/pdf/local_situation_covid19_en.pdf (accessed 2020 Aug. 31).

63. COVID-19 Canada Open Data Working Group. Epidemiological data from the COVID-19 outbreak in Canada. GitHub; 2020. Available: https://github. com/ishaberry/Covid19Canada (accessed 2020 Mar. 31).

64. COVID-19 in Canada: using data and modelling to inform public health action - technical briefing for Canadians. Ottawa: Public Health Agency of Canada; 2020. Available: www.canada.ca/content/dam/phac-aspc/documents/ services/diseases/2019-novel-coronavirus-infection/using-data-modelling-inform -eng.pdf (accessed 2020 Apr. 9).

65. Adam D. Special report: the simulations driving the world's response to COVID-19. Nature 2020;580:316-8.

66. Szklarski C. Why emergency departments look empty amid COVID-19 outbreak. CBC 2020 Mar. 26. Available: www.cbc.ca/news/health/covid-19-emergency -departments-canada-1.5510778 (accessed 2020 Apr. 9).

67. How Ontario is responding to COVID-19. Government of Ontario; 2020 Available: www.ontario.ca/page/how-ontario-is-responding-covid-19\#section-0 (accessed 2020 Jul. 24).

68. Payne E. Only $13 \%$ of Ontario's long-term care COVID patients went to hospital; advocates want to know why. Ottawa Citizen 2020 June 8. Available: https://ottawacitizen.com/news/local-news/only-13-of-ontarios-long-term-care -covid-patients-went-to-hospital-advocates-want-to-know-why (accessed 2020 Jul. 24)

69. Ferretti L, Wymant C, Kendall M, et al. Quantifying SARS-CoV-2 transmission suggests epidemic control with digital contact tracing. Science 2020;368:eabb6936. 2020 Mar. 31. [Epub ahead of print]. doi: 10.1126/science.abb6936.

70. Randolph HE, Barreiro LB. Herd immunity: understanding COVID-19. Immunity 2020;52:737-41.

Affiliations: Division of Infectious Diseases, Department of Medicine (Mishra, Coomes, Chan, Muller); MAP Centre for Urban Health Solutions (Mishra, Wang, Ma, Yiu, Landsman), Li Ka Shing Knowledge Institute, St. Michael's Hospital; Institute of Health Policy, Management and Evaluation (Paterson, Schull), University of Toronto; ICES (Paterson, Kim, Schull, Ishiguro); Decision Support (Pequegnat, Lee), Unity Health Toronto; Division of Infectious Diseases (Chan), Sunnybrook Health Sciences, University of Toronto; Infection Prevention and Control (Downing), St. Joseph's Health Centre, Unity Health Toronto; Department of Medicine (Straus), St. Michael's Hospital, University of Toronto; Infection Prevention and Control (Muller), St. Michael's Hospital, Unity Health Toronto, Toronto, Ont.

Contributors: Sharmistha Mishra, Linwei Wang, Huiting Ma and Matthew Muller conceived of and designed the study. Linwei Wang led model parameterization, justifications and internal validity checks. Huiting Ma led data analyses and figures. Linwei Wang led epidemic constraints and model analyses with Huiting Ma. Kristy Yiu led literature review with support from Eric Coomes. Kristy Yiu synthesized and 
collated all publicly available data for the GTA time series. All authors contributed to the acquisition and interpretation of data. Eliane Kim conducted the ICES analyses with J. Michael Paterson, Michael J. Schull and Lisa Ishiguro. Victoria Pequegnat and Anthea Lee conducted the Decision Support analyses. David Landsman developed the R Shiny tool. Sharmistha Mishra, Linwei Wang, Huiting Ma and Kristy Yiu drafted the manuscript; all authors contributed to revising the manuscript critically. All authors gave final approval to the version to be published and agreed to be held accountable for all aspects of the work.

Funding: The transmission modeling was supported by the Canadian Institutes of Health Research Foundation Grant (FN 13455), the Ontario Early Researcher Award (ER17-13-043) and the St. Michael's Hospital Foundation Research Innovation Council's 2020 COVID-19 Research Award. This study was supported by ICES, a non-profit research institute funded by the Ontario Ministry of Health and Long-Term Care.

Data sharing: Model code and data are available at https:/github.com/ mishra-lab/covid-GTA-surge-planning.

Acknowledgments: The authors thank the infection prevention and control practitioners and pandemic command centres at every health facility across the GTA who have come together as a working group, and whose efforts, solidarity and tireless work within each of their hospitals, guided the questions in this study. In particular, the authors thank the infection prevention and control teams and pandemic command centre at Unity Health Toronto for requesting and guiding the questions. The authors thank Jesse Knight for helpful feedback on the R Shiny tool. The authors thank Pavidra Ambiganithy, St. Michael's Hospital Infection Prevention and Control Team, for supporting the coordination surrounding data requests. Sharmistha Mishra is supported by Tier 2 Canada Research Chair in Mathematical Modeling and Program Science. Sharon Straus is supported by a Tier 1 Research Chair in Knowledge Translation and Quality of Care.

Supplemental information: For reviewer comments and the original submission of this manuscript, please see www.cmajopen.ca/content/8/3/ E593/suppl/DC1.

Disclaimer: This study was supported by ICES, which is funded by an annual grant from the Ontario Ministry of Health and Long-Term Care (MOHLTC). The opinions, results and conclusions reported in this article are those of the authors and are independent from the funding sources. No endorsement by ICES or the Ontario MOHLTC is intended or should be inferred. Parts of this material are based on data and information compiled and provided by the Ontario Ministry of Health and the Canadian Institute for Health Information. The analyses, conclusions, opinions and statements expressed herein are those of the authors and not necessarily those of the funding or data sources; no endorsement is intended or should be inferred. The study was also supported by Unity Health Toronto Decision Support Analyses. 